\title{
Nalbuphine Versus Ketorolac as an Adjuvant to Local Wound Infiltration Anesthesia in Open Colorectal Surgery: A Prospective Randomized Controlled Study
}

\author{
Yi-Feng Ren · Xi Fu • Yu-Ting Wang · Hong Liu • Xiao-Zhen Zheng • \\ Jing Liu $\cdot$ Lin-Jiong Li $\cdot$ Feng-Ming You (D)
}

Received: January 13, 2021 / Accepted: February 11, 2021 / Published online: February 24, 2021

(c) The Author(s) 2021

\begin{abstract}
Introduction: Adding adjuvants to local wound infiltration (LWI) provides long analgesic duration with fewer adverse effects. We aimed to compare the clinical effects of nalbuphine and ketorolac as an adjuvant to LWI in patients undergoing open colorectal cancer surgery.

Method: A total of 126 ASA I-III patients aged $\geq 18$ years who were scheduled for open colorectal cancer surgery were included. Patients were randomly assigned to receive LWI using $10 \mathrm{~mL} \quad 0.75 \%$ ropivacaine, with $20 \mathrm{~mL}$ normal saline (group R), $10 \mathrm{mg}$ nalbuphine in $1 \mathrm{~mL}$ (group $\mathrm{RN}$ ), or $25 \mathrm{mg}$ ketorolac in $0.8 \mathrm{~mL}$ (group RK). Analgesia duration was the primary
\end{abstract}

Yi-Feng Ren and Xi Fu have contributed equally as cofirst authors.

Supplementary Information The online version contains supplementary material available at https:// doi.org/10.1007/s40122-021-00246-z.

Y.-F. Ren · X. Fu · Y.-T. Wang · H. Liu · L.-J. Li (ه) .

F.-M. You $(\square)$

Hospital of Chengdu University of Traditional

Chinese Medicine, Chengdu, Sichuan, China

e-mail: lilinjiong@163.com

F.-M. You

e-mail: yfmdoc@163.com

X.-Z. Zheng · J. Liu

Department of Anesthesiology, Medical College of

Henan University, Kaifeng, Henan, China outcome. The total 48 -h postoperative morphine-equivalent consumption and additional rescue analgesia rates were recorded as key secondary outcomes.

Results: Among 126 patients randomized, 124 completed the trial. The duration until the first press of the analgesia pump was significantly shorter in group R (median: $320.0 \mathrm{~min}$ ) compared with group RN (median: $829.5 \mathrm{~min}$ ) and group RK (median: $820.0 \mathrm{~min})(P<0.001)$. The median difference in morphine consumption was $113.0 \mathrm{mg}$ for group $\mathrm{R}$ vs. group $\mathrm{RN}$ $(P<0.001)$, and $115.5 \mathrm{mg}$ for group $\mathrm{R}$ vs. group RK $(P<0.001)$. The proportion of patients using additional morphine within the first day after surgery in group $\mathrm{R}$ showed a higher relative risk (RR) compared with group RN (RR, 3.89; $P=0.001)$ and group RK (RR, 3.17; $P=0.001)$. There were no apparent differences between the $\mathrm{RN}$ and RK groups in any outcomes, whether in adjusted or unadjusted analysis.

Conclusions: Among patients undergoing open colorectal cancer surgery, both nalbuphine and ketorolac infiltration achieved equally prolonged duration of analgesia and reduced morphine consumption compared with ropivacaine alone after surgery, suggesting that the equivalent analgesic dose of nalbuphine and ketorolac as local anesthetic adjuvants in LWI could have a similar analgesic effect.

Trial Registration: ChiCTR1800019209. 
Keywords: Adjuvant; Ketorolac; Local wound infiltration; Nalbuphine; Open colorectal surgery

\section{Key Summary Points}

Why carry out this study?

Adding adjuvants to local wound infiltration (LWI) provides long analgesic duration with fewer adverse effects. However, there is no high-quality evidence for comparison of the clinical effects of nalbuphine and ketorolac as an adjuvant to LWI in patients undergoing open colorectal cancer surgery.

We hypothesized that both nalbuphine and ketorolac as an adjuvant for LWI would contribute to more outstanding results in prolonging postoperative analgesia and relieving acute pain than ropivacaine alone, and that ketorolac would be more effective in reducing acute postoperative pain than nalbuphine.

\section{What was learned from the study?}

The results showed that both nalbuphine and ketorolac infiltration prolonged the duration of analgesia and reduced morphine consumption compared with ropivacaine alone after open colorectal surgery.

The results of the present study suggest that ketorolac infiltration did not result in a clinically important improvement over nalbuphine infiltration.

Generally, the infiltration of these agents (nalbuphine and ketorolac) appears to be safe, but the results should be interpreted with caution as exploratory outcomes.

\section{DIGITAL FEATURES}

This article is published with digital features, including a summary slide, to facilitate understanding of the article. To view digital features for this article, go to https://doi.org/10.6084/ m9.figshare.13913348.

\section{INTRODUCTION}

Local wound infiltration (LWI), where the local anesthetic and/or other drugs are injected directly at the incision point, is a simple and effective analgesic procedure for large incision in abdominal surgery [1-3]. However, like nerve block, the insufficient analgesia time caused by local anesthetics used on their own is a major limitation of LWI $[3,4]$. Improvement in perioperative pain is more valuable than immediate postoperative pain relief $[5,6]$. To address these issues, opioids, nonsteroidal anti-inflammatory drugs (NSAIDs), dexmedetomidine, dexamethasone, ketamine, and magnesium are often used as adjuvants to local anesthetics to prolong the duration and enhance LWI efficacy $[3,7,8]$.

Opioids and NSAIDs are the two most essential analgesics. The analgesic effects of both opioids (nalbuphine) [9-11] and NSAIDs (ketorolac) [12-14] as local anesthetic adjuvants in various nerve blocks are well established compared with placebo. With regard to LWI, there is high-quality evidence that ketorolac 30-60 mg may be an effective infiltration agent, with peripheral analgesia beyond the effects of systemic absorption $[3,15,16]$. However, highquality randomized controlled trials should be conducted to confirm the results, as studies to date are of mixed quality [3]. On the other hand, it should be noted that while previous research indicated that nalbuphine provided longer and more effective postoperative analgesia as an adjuvant in intraspinal and nerve block, no study has confirmed the clinical effect of nalbuphine on LWI. To the best of our knowledge, there is no high-quality evidence for comparison of nalbuphine and ketorolac in LWI.

The safety of adjuvants, including nalbuphine and ketorolac, is largely unknown in 
the perioperative period. The rate of LWI-related adverse effects, such as drug infiltration complications, delayed wound healing, infection and pruritus, remains undefined, and it is critical that LWI not exacerbate these events. Although adjuvants have been associated with adverse outcomes in some settings, this association has not been fully investigated in LWI [3].

This trial investigating LWI with nalbuphine and ketorolac (LWINK) aimed to compare nalbuphine and ketorolac as an adjuvant to $0.25 \%$ ropivacaine for LWI anesthesia in patients undergoing open colorectal surgery. The hypotheses were as follows: (1) Both nalbuphine and ketorolac as an adjuvant for LWI would contribute to more outstanding results in prolonging postoperative analgesia and relieving acute pain compared with ropivacaine alone. (2) Ketorolac would be more effective in reducing acute postoperative pain than nalbuphine. (3) Neither nalbuphine nor ketorolac would increase the risk of LWI-related adverse effects.

\section{METHODS}

\section{Trial Design and Participants}

Before patient enrollment, the trial was approved by the Ethical Committee of Henan University (registration no. 2018LW012) on October 20, 2018. The trial was conducted in accordance with the Declaration of Helsinki and registered at the Chinese Clinical Trial Registry (registration no. ChiCTR1800019209, chictr.org.cn). The actual research start date was November 15, 2018, and the main actual completion date was December 31, 2019. A data and safety monitoring board (DSMB) was established to oversee the safety of the study and check the integrity of data.

This LWINK trial was a single-center, prospective, randomized, double-blind study. Patients with American Society of Anesthesiologists (ASA) physical status classes I-III, aged 28-80 years and scheduled for open colorectal surgery were considered eligible to participate in the study after providing written informed consent. Major exclusion criteria included allergy to the study drugs (local anesthetics, opioids and NSAIDs); chronic pain treatment or chronic steroid therapy [17]; psychiatric disorders; neuromuscular or endocrine diseases; diabetes mellitus; coagulopathy; cardiac, liver or renal diseases; and pregnant and lactating women. Those who underwent laparoscopic surgery, were sent to the intensive care unit after the operation, presented severe postoperative infection, or refused to participate in the study were also excluded from the study.

\section{Randomization and Blinding}

A computer-generated simple randomization list was used to classify the patients into three groups at a 1:1:1 ratio using IBM SPSS Statistics for Windows, version 25.0 (IBM Corp. Armonk, NY, USA). The three groups were as follows: group $\mathrm{R} \quad(n=41): 10 \mathrm{~mL}$ of ropivacaine $0.75 \%+20 \mathrm{~mL}$ normal saline; group $\mathrm{RN}$ $(n=42): 10 \mathrm{~mL}$ of ropivacaine $0.75 \%+19 \mathrm{~mL}$ normal saline + subcutaneous injection of nalbuphine $(10 \mathrm{mg})$ in $1 \mathrm{~mL}$; and group $\mathrm{RK}$ $(n=41): \quad 10 \mathrm{~mL} \quad$ of $\quad$ ropivacaine $0.75 \%+19.2 \mathrm{~mL}$ normal saline + subcutaneous ketorolac $(25 \mathrm{mg})$ in $0.8 \mathrm{~mL}$.

Intravenous nalbuphine or ketorolac was not administered to all patients perioperatively. Before the operation, an anesthesiologist, blind to the groups, evaluated the preoperative status of the patients to determine whether they met the inclusion criteria of the study. All patients were taught how to use patient-controlled intravenous analgesia (PCIA) and the numerical rating scale (NRS, with 0 : no pain, to 10 : the worst imaginable pain). The randomization numbers were stored in a locked container in the operating room. A nurse who did not participate in the trial opened the appropriate numbered envelope and prepared the drugs. The syringe cylinder was covered using the same opaque material for uniformity. Incision length was measured before skin closure, and the group of surgeons who were not involved in the study performed the LWI. 


\section{Anesthesia Procedure}

All patients were instructed to fast for $8 \mathrm{~h}$ and refrain from intake of water for $4 \mathrm{~h}$. In the operating room, peripheral venous access was established, and an infusion of a lactated Ringer's solution was initiated. Five-lead electrocardiogram (ECG), heart rate (HR), noninvasive blood pressure (BP), respiratory rate (RR), and pulse oxygen saturation $\left(\mathrm{SpO}_{2}\right)$ were continuously monitored. Radial artery catheterization was performed to measure mean arterial pressure (MAP). Catheterization was conducted via the right internal jugular vein or right subclavian vein to monitor central venous pressure (CVP).

General anesthesia was induced with $0.5 \mu \mathrm{g} /$ $\mathrm{kg}$ of sufentanil, $0.15-0.30 \mathrm{mg} / \mathrm{kg}$ of etomidate, and $0.2 \mathrm{mg} / \mathrm{kg}$ of cisatracurium. Etomidate, sevoflurane, remifentanil and cisatracurium were used to maintain the bispectral index (BIS) at 40-60, thereby maintaining anesthesia. After the operation, all patients were connected to the prepared PCIA pump and sent to the postanesthesia care unit (PACU) for further observation.

\section{Pain Management}

Standardized analgesia was used in patients as follows: (1) The drug was infiltrated into the tissues around the entire incision, including the muscles and subcutaneous tissue, with $1 \mathrm{~mL}$ of drug per $1 \mathrm{~cm}$ incision. (2) For postoperative analgesia, all patients received PCIA. PCIA was administered for NRS $\geq 4$ or upon patient request. The analgesic pump configuration was as follows: $2.0 \mu \mathrm{g} / \mathrm{kg}$ sufentanil diluted to $100 \mathrm{~mL}(0.5 \mathrm{~mL}$ bolus, a lockout time interval of $15 \mathrm{~min}$ and $1 \mathrm{~h}$ of $2 \mathrm{~mL}$ without any baseline infusion). (3) During early recovery in the PACU, rescue intramuscular morphine was given as needed when NRS was $\geq 4$; tropisetron $5 \mathrm{mg}$ was injected intravenously when nausea and vomiting occurred. (4) In the ward, additional rescue analgesia measures (intravenous morphine $5 \mathrm{mg}$ ) were taken whenever the PCIA analgesic effect was still unsatisfactory.

\section{Trial Outcomes}

The primary outcome was analgesia duration, defined as the time in minutes to the first press of the analgesia pump. The total morphineequivalent consumption over the 48 -h postoperative period and the additional rescue analgesia rates for the three groups were recorded within 2 days after surgery as key secondary outcomes. The total morphine-equivalent consumption included both sufentanil dose in the PCIA pump and rescue morphine dose. We employed a published equivalence formula, cumulative opioid consumption with opioid drugs other than morphine converted to morphine-equivalent doses, where $10 \mathrm{mg}$ intravenous (i.v.) morphine $=0.01 \mathrm{mg}$ i.v. sufentanil. Other secondary outcomes were NRS (score range, 0 [no pain] to 10 [worst imaginable pain]) scores on resting and moving (taking a deep breath) at $2,4,8,12,24,48$, and $72 \mathrm{~h}$ postoperatively. Adverse events (nausea, vomiting, local anesthetic toxicity, hypotension, bradycardia, gastrointestinal bleeding, pruritus and wound infection) from 0 to $48 \mathrm{~h}$ were also recorded as exploratory outcomes.

\section{Sample Size}

We conducted a preliminary study of 15 patients (five per group) and calculated the sample size according to the primary outcome. The calculation of sample size and power of the test were performed using PASS software version 15 (NCSS, Kaysville, UT, USA). One-way analysis of variance (ANOVA) was selected and grouped into three groups; the group allocation ratio was $1: 1: 1$, with hypothesized means of $381.3,607.5$ and 620.9 and SD of 107.5, 133.1, and 142.7, respectively. The required sample size for each group was calculated to be 36 at a power $(1-\beta)$ of 0.90 , and a Bonferroni-corrected alpha error of 0.01 [17]. It was estimated to be at least 40 per group considering 10\% dropouts and incomplete follow-up. 


\section{Statistical Analysis}

Statistical analysis was performed by an independent statistician (CGN) with IBM SPSS v25.0 and R software (Version 3.5.3, R Foundation for Statistical Computing). The modified intentionto-treat data were used for analysis with no planned interim analysis. We did not address the missing data because the data for postoperative assessments were less than 5\%. All reported $P$ values are two-tailed.

All data were checked for normal distribution with the Kolmogorov-Smirnov test. Continuous data are presented as mean with a confidence interval (CI) or standard deviation (SD) for normally distributed variables and medians with CI for non-normally distributed data. Categorical variables are summarized using numbers (proportions) or proportions with CI.

The main analysis of the primary outcome of duration of analgesia employed pairwise comparisons between groups using the Kruskal-Wallis test followed by Dunn-Bonferroni post hoc comparison for non-normally distributed data. Changes between groups are presented as median differences and CIs. The threshold for type I errors was adjusted to 0.05/ $3=0.017$ for the pairwise comparisons between the three groups (three comparisons) for the primary outcome of analgesia duration [18]. For time-to-event outcomes (duration of analgesia), we analyzed the data using the Kaplan-Meier survival method and compared the groups using the log-rank test, with adjustment for multiple comparisons to ensure the reliability of results [17].

Generalized estimating equations (GEE) with robust standard error estimates were used to account for repeated measures of NRS data $[18,19]$. The level of significance and corresponding CI were 0.001 and $99.9 \%$ for other secondary outcomes of NRS scores. Because all patients reported pain, sensitivity analyses were not performed to evaluate the statistical nature of the missing data (NRS $=0$ was considered as missing data) [20].

Categorical data (rescue analgesia rates and the incidence of side effects) were analyzed using the Pearson $\chi^{2}$ test or Fisher exact test, as appropriate. $P<0.017$ (Bonferroni adjusted) was considered statistically significant for comparisons of rescue analgesia rates between groups, and the differences between groups were calculated using relative risk (RR) with 98.3\% CI using the mean difference. The level of significance and corresponding confidence interval were set at 0.05 and $95 \%$ for the incidence of side effects [18].

Additionally, secondary analyses included adjusted analyses (for sex, age, wound length, and type of surgery) for the primary outcome and the key secondary outcomes. The adjusted analyses were tested for interaction with three groups by the GEE approach using the gee package in $\mathrm{R}$ software [18]. The results of the secondary analysis were interpreted as exploratory only.

\section{RESULTS}

\section{Patient Characteristics}

A total of 153 participants were enrolled in this trial. However, 27 patients were disqualified for failing to meet the inclusion criteria or refusing to participate. Following randomization, no patients were canceled because of nonadherence to the protocol; thus, the remaining 126 patients were assigned to one of three groups, and 124 patients completed the study (Fig. 1). The patient characteristics (demographic, surgical and intraoperative medication use) were comparable between the three groups (Table 1).

\section{Primary Outcome}

The median duration of analgesia in group $\mathrm{R}$ was $320.0 \mathrm{~min}$ (98.3\% CI 308.5-332.0), and was $829.5 \mathrm{~min}$ (98.3\% CI, 780.0 to 860.0 ) in group $\mathrm{RN}$ and $820.0 \mathrm{~min}$ (98.3\% CI 812.0-877.0) in group RK. In the pairwise comparisons, the median difference was $492.0 \mathrm{~min}(98.3 \% \mathrm{CI}$ 459.0-526.8; $P<0.001)$ between group $\mathrm{R}$ and group RN, and $513.0 \mathrm{~min}(98.3 \%$ CI 489.4-539.2; $P<0.001$ ) between groups $\mathrm{R}$ and RK. However, there was no significant 


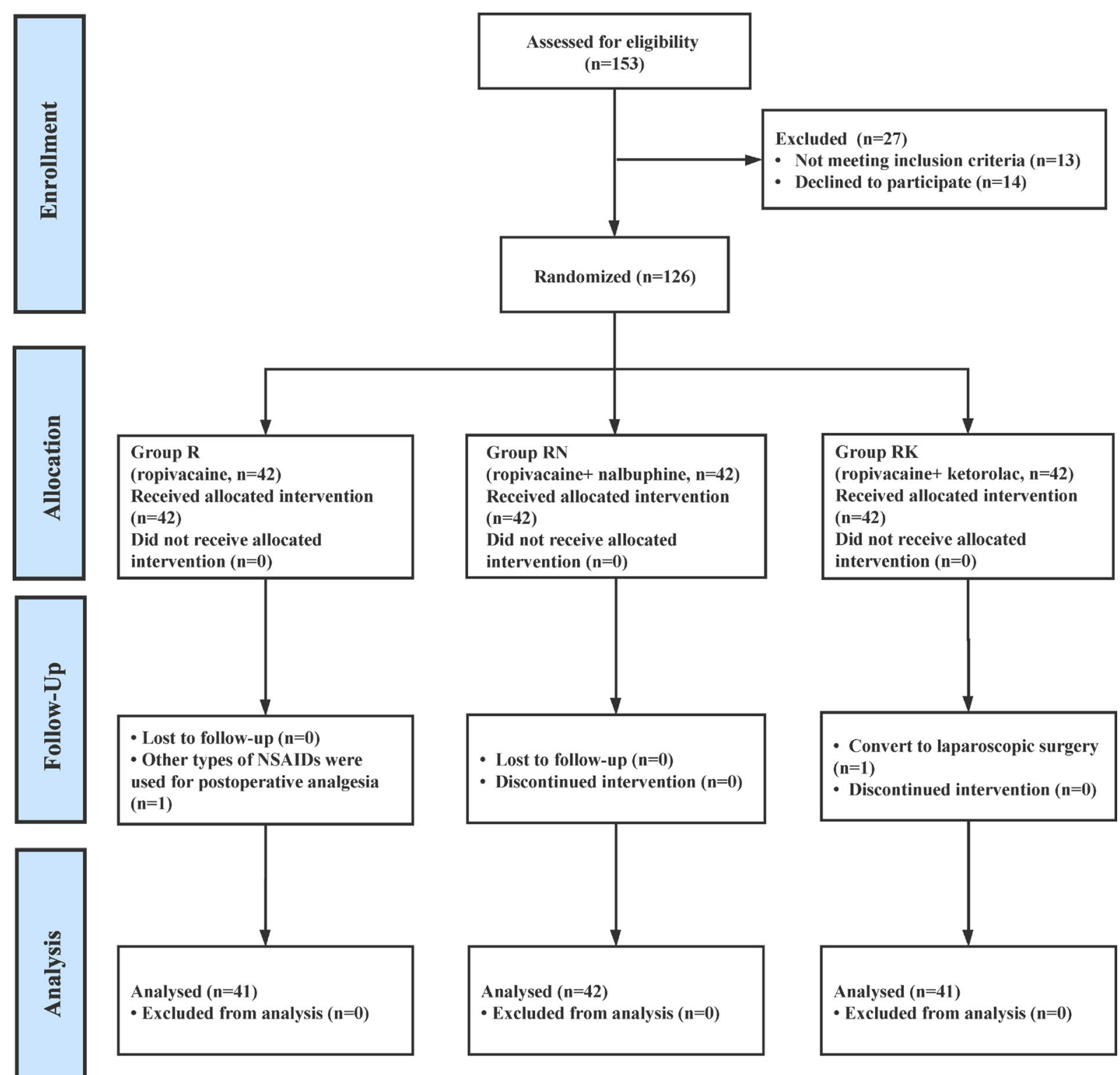

Fig. 1 Participant flow of the progress through the phases of the trial. $R$ ropivacaine, $R N$ ropivacaine + nalbuphine, $R K$ ropivacaine + ketorolac

difference between group RN and group RK (19.5 $\min [98.3 \% \mathrm{CI}-49.1$ to 11.2$] ; P=0.83$ ) (Table 2).

The Kaplan-Meier survival analysis of the time to the first press of the analgesia pump is shown in Fig. 2. The results of log-rank tests were consistent with the Kruskal-Wallis test. Secondary analyses revealed a similar result as in the main unadjusted analysis (see Table S1 in the electronic supplementary material for details).

\section{Key Secondary Outcomes}

The total 48-h postoperative morphine-equivalent consumption in group $\mathrm{R}$ was $211.0 \mathrm{mg}$ (98.3\% CI 209.5-216.0), and it was $99.3 \mathrm{mg}$ (98.3\% CI 97.0-101.3) in group RN and $96.6 \mathrm{mg}$ 
Table 1 Demographic data and surgical characteristics

\begin{tabular}{|c|c|c|c|}
\hline & Group $\mathrm{R}(n=41)$ & Group RN $(n=42)$ & Group RK $(n=41)$ \\
\hline \multicolumn{4}{|l|}{ Gender } \\
\hline Male & $19(46)$ & $19(45)$ & $20(49)$ \\
\hline Female & $22(54)$ & $23(55)$ & $21(51)$ \\
\hline Age, mean $(\mathrm{SD})$, years & $65.1(11.0)$ & $66.5(9.5)$ & $66.8(9.9)$ \\
\hline Height, mean (SD), cm & $171.1(4.3)$ & $169.9(5.2)$ & $170.3(5.3)$ \\
\hline Weight, mean (SD), kg & $65.2(4.5)$ & $64.7(4.7)$ & $65.5(5.1)$ \\
\hline \multicolumn{4}{|l|}{ ASA score } \\
\hline 1. Healthy & $20(49)$ & $18(43)$ & $19(46)$ \\
\hline 2. Mild systemic disease & $15(36)$ & $16(38)$ & $17(42)$ \\
\hline 3. Severe systemic disease & $6(15)$ & $8(19)$ & $5(12)$ \\
\hline \multicolumn{4}{|l|}{ Surgery } \\
\hline Right hemicolectomy & $12(29)$ & $14(33)$ & $13(32)$ \\
\hline Left hemicolectomy & $14(34)$ & $15(36)$ & $12(29)$ \\
\hline Sigmoidectomy & $10(25)$ & $9(21)$ & $11(27)$ \\
\hline Anterior resection & $2(5)$ & $2(5)$ & $3(7)$ \\
\hline Panproctocolectomy & $3(7)$ & $2(5)$ & $2(5)$ \\
\hline \multicolumn{4}{|l|}{ Intraoperative medication use } \\
\hline Sufentanil, mean (range) $(\mu \mathrm{g})$ & $32.6(29.0-37.5)$ & $32.4(28.0-37.5)$ & $32.8(28.5-38.5)$ \\
\hline Sevoflurane, mean (range) (mL) & $25.8(19.5-34.6)$ & $25.4(19.1-33.7)$ & $25.5(18.9-34.1)$ \\
\hline Remifentanil, mean (range) (mg) & $3.3(1.6-4.9)$ & $3.1(2.0-5.1)$ & $2.9(1.9-5.3)$ \\
\hline Tropisetron & $19(46)$ & $20(48)$ & $20(49)$ \\
\hline Duration of surgery, mean (SD) (min) & $157.9(16.5)$ & $158.7(15.8)$ & $159.0(15.5)$ \\
\hline Wound length, mean $(\mathrm{SD})(\mathrm{cm})$ & $19.65(1.0)$ & $20.2(1.1)$ & $19.6(0.9)$ \\
\hline
\end{tabular}

$A S A$ American Society of Anesthesiologists, $S D$ standard deviation, $R$ ropivacaine, $R N$ ropivacaine + nalbuphine, $R K$ : ropivacaine + ketorolac

Data are reported as numbers (\%) unless otherwise indicated

(98.3\% CI 94.5-99.0) in group RK. Patients in group RN (median difference, $113.0 \mathrm{mg} ; 98.3 \%$ CI 109.5-116.0; $P<0.001)$ and group RK (median difference, $115.5 \mathrm{mg} ; \quad 98.3 \% \quad$ CI 112.0-119.0; $P<0.001$ ) experienced lower 48 -h postoperative total morphine-equivalent consumption compared with group $\mathrm{R}$. There was no significant difference between group $\mathrm{RN}$ and group RK (2.6 mg [98.3\% CI 0.0-5.4]; $P=0.022)$ (Table 3).

The proportion of additional rescue analgesia rates within the first day after surgery in group R was $46.3 \%$ (98.3\% CI 27.8-65.7), and it was $11.9 \%(98.3 \%$ CI 3.0-28.8) in group RN and $14.6 \%(98.3 \%$ CI $4.4-32.4)$ in group RK. In a post hoc analysis, group $\mathrm{R}$ showed a higher RR 
Table 2 Between-group comparisons of duration of analgesia

\begin{tabular}{|c|c|c|c|}
\hline & Group $\mathbf{R}$ & Group RN & Group RK \\
\hline Duration of analgesia, median $(98.3 \% \mathrm{CI})(\mathrm{min})$ & $\begin{array}{l}320.0 \\
\quad(308.5-332.0)\end{array}$ & $829.5(780.0-860.0)$ & $820.0(812.0-877.0)$ \\
\hline \multicolumn{4}{|l|}{ Difference } \\
\hline $\begin{array}{l}\text { Compared with group R (median) }(98.3 \% \mathrm{CI}) \text {, } \\
\min ^{\mathrm{a}}\end{array}$ & NA & $\begin{array}{l}-492.0(-526.8 \text { to } \\
-459.0)\end{array}$ & $\begin{array}{l}-513.0(-539.2 \text { to } \\
-489.4)\end{array}$ \\
\hline$P$ value $^{\mathrm{b}}$ & & $P<0.001$ & $P<0.001$ \\
\hline $\begin{array}{l}\text { Compared with group } \mathrm{RN} \text {, median }(98.3 \% \mathrm{CI}) \\
(\mathrm{min})^{\mathrm{a}}\end{array}$ & NA & NA & $-19.5(-49.1$ to 11.2$)$ \\
\hline$P$ value $^{\mathrm{b}}$ & & & $P=0.83$ \\
\hline $\begin{array}{l}\text { Compared with group } \mathrm{RK} \text {, median }(98.3 \% \mathrm{CI}) \\
(\mathrm{min})^{\mathrm{a}}\end{array}$ & NA & NA & NA \\
\hline$P$ value ${ }^{\mathrm{b}}$ & & & \\
\hline
\end{tabular}

$N A$ not applicable, $C I$ confidence interval, $R$ ropivacaine, $R N$ ropivacaine + nalbuphine, $R K$ ropivacaine + ketorolac

a Confidence intervals were calculated by Hodges-Lehmann estimation to estimate the median difference

b $P$ values were calculated using Kruskal-Wallis test

for patients using additional morphine compared with group RN (RR, 3.89 [98.3\% CI 12.4-56.5]; $P=0.001)$ and group RK (RR, 3.17 [98.3\% CI 8.9-54.5]; $P=0.001)$. There was no significant difference between group $\mathrm{RN}$ and group RK (RR, 0.81 [98.3\% CI -20.5 to 15.0 ]; $P=0.72$ ). Although group $\mathrm{R}$ also showed a higher RR compared with group RN $(\mathrm{RR}=1.79)$ and group $\mathrm{RK}(\mathrm{RR}=2.33)$ for patients using additional morphine within the second day after surgery, there was no significant difference in group comparisons by post hoc analysis (Table 3).

In all key secondary outcomes of adjusted analysis, the findings remained robust and results failed to demonstrate any significant differences between nalbuphine infiltration and ketorolac infiltration (see Table S2 in the electronic supplementary material for details).

\section{Other Secondary Outcomes}

By NRS measurements, there were no apparent differences in pain between the three groups at $2,24,48$, and $72 \mathrm{~h}$ post-operation on resting state. However, NRS pain scores were significantly lower in group $\mathrm{RN}$ and group $\mathrm{RK}$ than in group $\mathrm{R}$ from 4 to $12 \mathrm{~h}$ after arrival at the ward $(P<0.001$ for all time points) (see Fig. 3a and Table S3 in the electronic supplementary). Group R had higher pain scores than group RN and group RK at 4, 8, 12 and $24 \mathrm{~h}$ when taking a deep breath compared with the resting state pain scores. There were no significant differences in pain between group $\mathrm{RN}$ and group $\mathrm{RK}$ under either resting or moving conditions at any of the postoperative intervals $(P=1.00)$ (see Fig. $3 \mathrm{~b}$ and Table $\mathrm{S} 4$ in the electronic supplementary).

\section{Exploratory Outcomes}

The proportions of patients with one or more adverse events in group R were 14.6\% (95\% CI 5.6-29.2), $14.3 \%$ (95\% CI 5.4-28.5) in group RN and $12.2 \%$ (95\% CI 4.1-26.2) in group RK. Adverse events did not differ significantly in any pairwise comparison (all $P$ values $>0.05$ ) (Table 4). 


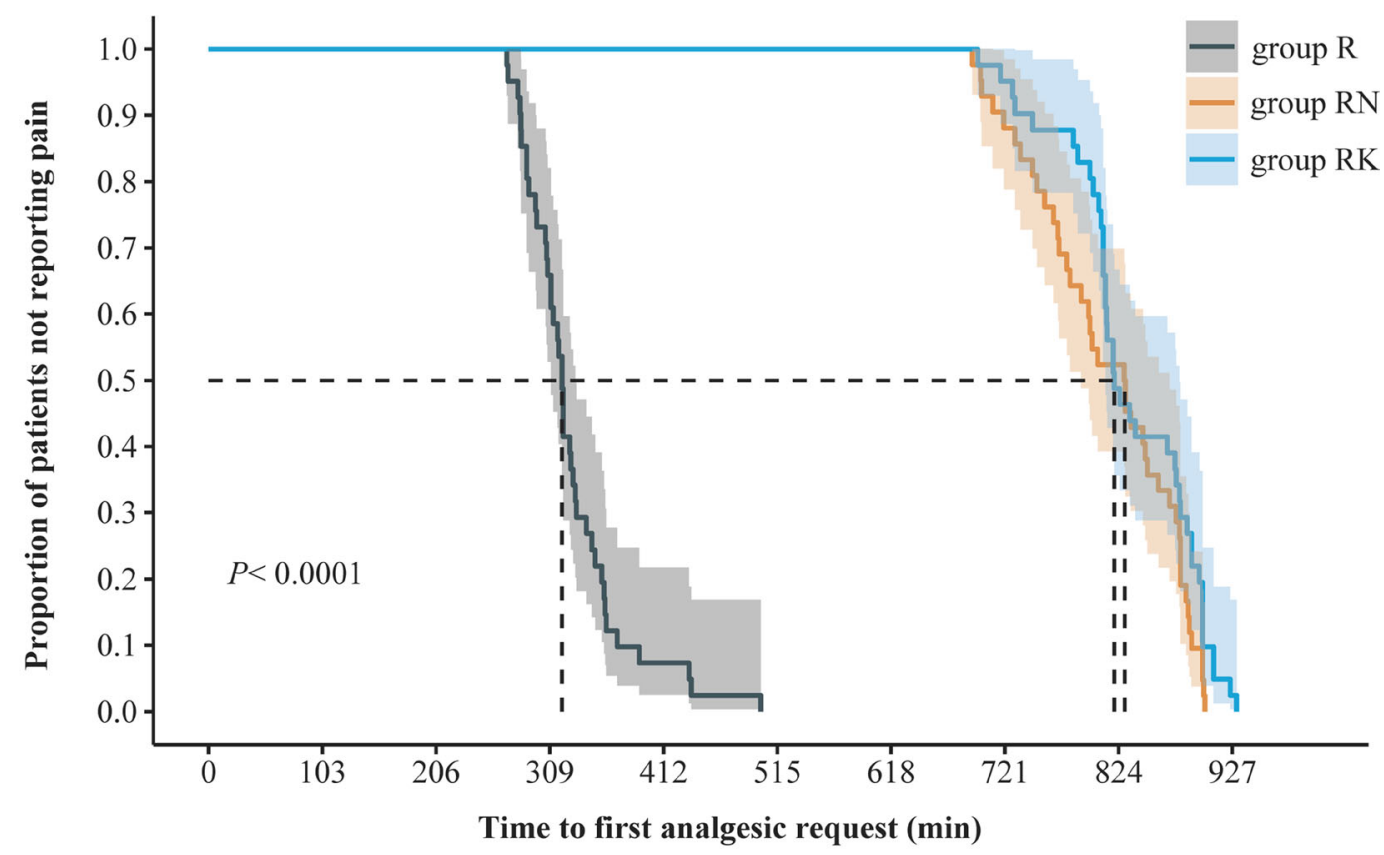

Number at risk

$\begin{array}{lcccccccccc}\text { group R } & 41 & 41 & 41 & 27 & 3 & 0 & 0 & 0 & 0 & 0 \\ \text { group RN } & 42 & 42 & 42 & 42 & 42 & 42 & 42 & 37 & 22 & 0 \\ \text { group RK } & 41 & 41 & 41 & 41 & 41 & 41 & 41 & 39 & 20 & 1\end{array}$

Fig. 2 Kaplan-Meier analysis for the first analgesic request in the three groups. $R$ ropivacaine, $R N$ ropivacaine + nalbuphine, $R K$ ropivacaine + ketorolac

\section{DISCUSSION}

In this study, we explored the potential benefit of nalbuphine and ketorolac as an adjuvant for LWI in prolonging postoperative analgesia and relieving acute pain compared with ropivacaine alone. We hypothesized that nalbuphine and ketorolac as ropivacaine adjuvant could result in a longer duration of analgesia than ropivacaine alone and that ketorolac would be more effective in reducing acute postoperative pain than nalbuphine, but the results did not fully confirm these hypotheses. Both nalbuphine and ketorolac infiltration prolonged the duration of analgesia and reduced the additional rescue analgesia rates and the postoperative consumption of morphine. As reported for other peripheral nerve blocks, our results show that nalbuphine and ketorolac infiltration have a postoperative opioid-sparing effect $[10,16]$. In addition, postoperative NRS pain scores within
$12 \mathrm{~h}$ were lower in both the nalbuphine and the ketorolac infiltration groups compared with the ropivacaine alone group. The clinical relevance of these differences is likely high, as pain scores throughout the study period suggested adequate analgesia in both groups, with statistical significance. The adverse events were low in the three groups, with no significant differences.

The relatively restricted duration of local anesthetics used on their own is a major limitation of LWI. In addition, there remain clinical gaps in the use of different types of adjuncts to enhance the effectiveness of LWI [3, 7]. Nalbuphine, a mixed agonist-antagonist opioid, was found to prolong the duration of analgesia in supraclavicular brachial block, subarachnoid block and epidural block as an adjuvant to local anesthetics. To the best of our knowledge, this aspect of nalbuphine infiltration has not been previously investigated [9-11], and Johnny-Wei et al. reported a systematic review showing 35 
Table 3 Key secondary outcomes

\begin{tabular}{|c|c|c|c|}
\hline & Group R & Group RN & Group RK \\
\hline $\begin{array}{l}\text { 48-h Total morphine equivalent administered, median } \\
\qquad(98.3 \% \mathrm{CI})(\mathrm{mg})^{\text {a, b }}\end{array}$ & $\begin{array}{l}211.0 \\
\quad(209.5-216.0)\end{array}$ & $99.3(97.0-101.3)$ & $96.6(94.5-99.0)$ \\
\hline \multicolumn{4}{|l|}{ Difference, median (98.3\% CI) (mg) } \\
\hline Compared with group $\mathrm{R}$ & NA & $\begin{array}{l}113.0 \\
(109.5-116.0)\end{array}$ & $115.5(112.0-119.0)$ \\
\hline$P$ value & & $P<0.001$ & $P<0.001$ \\
\hline Compared with group $\mathrm{RN}$ & NA & NA & $2.6(0.0-5.4)$ \\
\hline$P$ value & & & $P=0.022^{\mathrm{c}}$ \\
\hline Compared with group RK & NA & NA & NA \\
\hline \multicolumn{4}{|l|}{$P$ value } \\
\hline \multicolumn{4}{|l|}{ Additional rescue analgesia rates within 2 days post-surgery } \\
\hline POD-1 $(98.3 \% \mathrm{CI})(\%)^{\mathrm{d}}$ & $\begin{array}{l}46.3 \\
(27.8-65.7)\end{array}$ & $11.9(3.0-28.8)$ & $14.6(4.4-32.4)$ \\
\hline \multicolumn{4}{|l|}{ Absolute difference (RR) [98.3\% CI] (\%) } \\
\hline Compared with group $\mathrm{R}$ & NA & $\begin{array}{l}34.4(3.89) \\
\quad[12.4-56.5]\end{array}$ & $\begin{array}{l}31.7(3.17) \\
\quad[8.9-54.5]\end{array}$ \\
\hline$P$ value & & $P=0.001$ & $P=0.002$ \\
\hline Compared with group $\mathrm{RN}$ & NA & NA & $\begin{array}{l}-2.7(0.81)[-20.5 \text { to } \\
15.0]\end{array}$ \\
\hline$P$ value & & & $P=0.72$ \\
\hline Compared with group RK & NA & NA & NA \\
\hline \multicolumn{4}{|l|}{$P$ value } \\
\hline POD-2 (98.3\% CI) $(\%)^{\mathrm{d}}$ & $\begin{array}{l}17.1(5.8 \text { to } \\
35.3)\end{array}$ & $9.5(1.9-25.7)$ & $7.3(1.0-22.9)$ \\
\hline \multicolumn{4}{|l|}{ Absolute difference (RR) [98.3\% CI] (\%) } \\
\hline Compared with group $\mathrm{R}$ & NA & $\begin{array}{l}7.6(1.79)[-10.2 \text { to } \\
25.3]\end{array}$ & $\begin{array}{l}9.8(2.33)[-7.3 \text { to } \\
26.8]\end{array}$ \\
\hline$P$ value & & $P=0.31^{\mathrm{e}}$ & $P=0.18^{\mathrm{e}}$ \\
\hline Compared with group $\mathrm{RN}$ & NA & NA & $\begin{array}{l}2.2(1.30)[-12.3 \text { to } \\
16.7]\end{array}$ \\
\hline$P$ value & & & $P=0.72^{\mathrm{e}}$ \\
\hline Compared with group RK & NA & NA & NA \\
\hline
\end{tabular}


Table 3 continued

\begin{tabular}{llll}
\hline & Group $\mathbf{R}$ & Group RN & Group RK \\
\hline$P$ value & & & \\
\hline
\end{tabular}

$N A$ not applicable, $C I$ confidence interval, $R R$ relative risk, $P O D$ postoperative day; $R$ ropivacaine, $R N$ ropivacaine + nalbuphine, $R K$ ropivacaine + ketorolac

a Total morphine equivalent is calculated as the sum of (sufentanil dose $[\mu \mathrm{g}] \times 1)+$ morphine dose

b Confidence intervals were calculated by the Hodges-Lehmann estimator to determine the median difference. $P$ values were calculated using Kruskal-Wallis test

c This $P$ value $=0.022$ is above the prespecified threshold (level of significance) of $P=0.017$

d The $98.3 \%$ confidence intervals for proportions were calculated using Clopper-Pearson method with binom.test

e Fisher's exact test

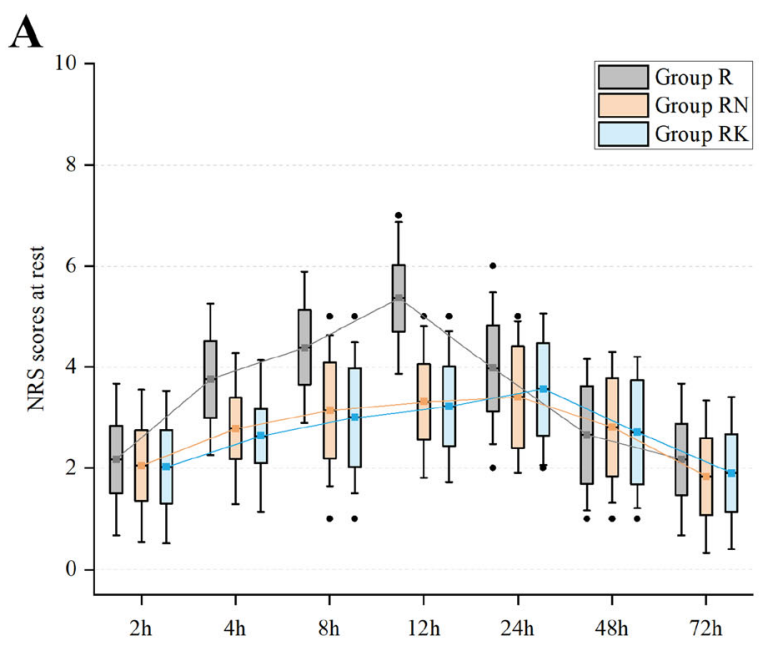

Fig. 3 NRS pain scores at 2, 4, 8, 12, 24, 48 and $72 \mathrm{~h}$ postoperatively after surgery in the three groups; a at rest; b on moving (taking a deep breath). NRS numerical rating scale, $R$ ropivacaine, $R N$ ropivacaine + nalbuphine, $R K$ ropivacaine + ketorolac. Top and bottom of boxes

randomized controlled trials examining opioid wound infiltration, which is the most wellstudied class [3].

Although some studies have shown the existence of opioid receptors in the peripheral neurons, the peripheral mechanisms of opioid wound infiltration are unclear. We preliminarily determined that surgery and the ensuing inflammation could lead to the upregulation of opioid receptors at peripheral nerve endings

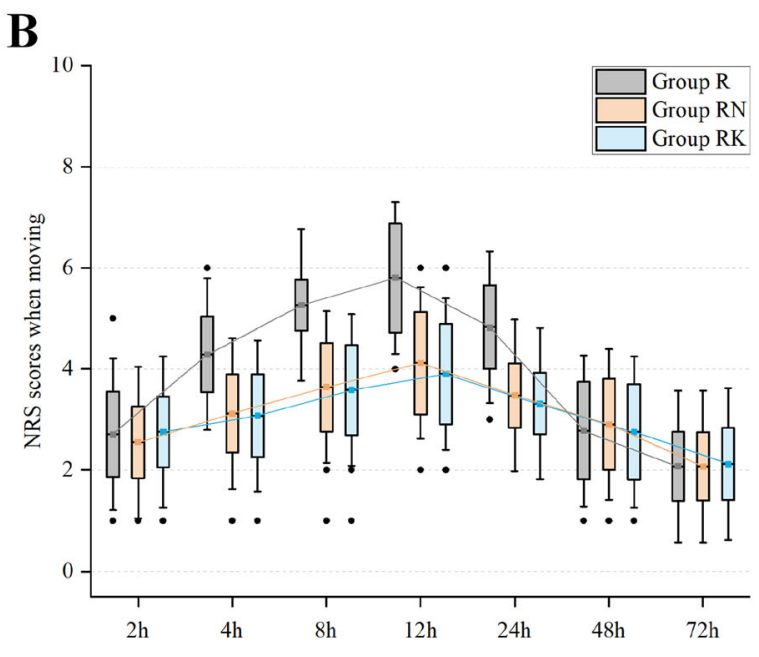

indicate standard deviation; center lines indicate means. Tukey error bars are shown, which extend to the farthest points that are not outliers. Outliers (black circles) were defined as values greater than 1.5 times the standard deviation

and enhanced sensitivity of the opioids at these sites [21, 22]. Locally infiltrated opioids act on opioid receptors in peripheral tissues and nerves, while producing anti-inflammatory effects by reducing substance $\mathrm{P}$ and norepinephrine [23]. In addition to their opioid effects, another possible analgesic mechanism is the blocking of nerve conduction through a voltage-gated sodium channel [24, 25]. Of course, the altered $\mathrm{pH}$ of local anesthetic 
Table 4 Exploratory outcomes

\begin{tabular}{|c|c|c|c|c|}
\hline & Group R & Group RN & Group RK & $P$ value \\
\hline Total adverse events in $48 \mathrm{~h}$ post-surgery (95\% CI) (\%) & $14.6(5.6-29.2)$ & $14.3(5.4-28.5)$ & $12.2(4.1-26.2)$ & $0.942^{\mathrm{a}}$ \\
\hline \multicolumn{5}{|l|}{ Types of Adverse Events, (95\% CI) (\%) } \\
\hline Nausea & $4.9(0.6-16.5)$ & $4.8(0.6-16.2)$ & $2.4(0.1-12.9)$ & $0.818^{\mathrm{b}}$ \\
\hline Vomiting & $4.9(0.6-16.5)$ & $2.4(0.1-12.6)$ & $2.4(0.1-12.9)$ & $0.765^{\mathrm{b}}$ \\
\hline Local anesthetic toxicity & 0 & 0 & 0 & - \\
\hline Hypotension & $2.4(0.1-12.9)$ & $4.8(0.6-16.2)$ & $4.9(0.6-16.5)$ & $0.818^{b}$ \\
\hline Bradycardia & $2.4(0.1-12.9)$ & $2.4(0.1-12.6)$ & $2.4(0.1-12.9)$ & $1.0^{\mathrm{b}}$ \\
\hline Gastrointestinal bleeding & 0 & 0 & 0 & - \\
\hline Pruritus & 0 & 0 & 0 & - \\
\hline Wound infection & 0 & 0 & 0 & - \\
\hline
\end{tabular}

solutions resulting from the addition of adjuvants can also prolong analgesic duration [11].

The exact mechanism of local corticosteroid is also poorly understood. The possible analgesia mechanisms of NSAID infiltration include inhibition of peripheral prostaglandin synthesis, a decrease in inflammatory mediators, suppression of neuronal discharge, and reduction in transmission in nociceptive $C$ fibers [26]. Bai et al. reported that there exists strong evidence that ketorolac 30-60 mg co-infiltration with local anesthetic reduces opioid requirements, prolongs analgesia duration, and reduces pain scores [3]. They also recommended further high-quality studies, though ketorolac showed great potential as an infiltration adjunct.

In terms of dose selection of the two adjuvants, ketorolac 30-60 mg appears to be an effective infiltration agent, with peripheral analgesia beyond the effects of general systemic absorption [3]. In previous studies, the analgesic effect of $10 \mathrm{mg}$ nalbuphine was better than $5 \mathrm{mg}$, with reduced side effects [27]. We therefore used $10 \mathrm{mg}$ nalbuphine in this study. Ketorolac dose was calculated based on that of nalbuphine $(10 \mathrm{mg}$ nalbuphine i.v. $=10 \mathrm{mg}$ morphine i.v. $=25 \mathrm{mg}$ ketorolac i.v.), and was slightly lower than $30 \mathrm{mg}$ (a minimum dose of peripheral analgesia beyond the effects of systemic absorption) [19]. It is not difficult to explain why our results deviate from our assumptions-in other words, there might be a significant difference between ketorolac and nalbuphine infiltration groups if the dose of ketorolac infiltration dose were increased.

While both ketorolac and nalbuphine infiltration reduced opioid use in this study, their roles in reducing postoperative nausea and vomiting after open colorectal surgery yielded contradictory results. Normally, reducing opioid consumption is closely related to a decrease in nausea and vomiting [9]. However, the small sample size of our study and among-individuals differences may partially explain this phenomenon. Therefore, further studies in a larger sample size are needed to truly elucidate the effect of adjuvants infiltration on aspects of nausea and vomiting.

This study has several limitations. First, although powered to detect a difference in duration of analgesia between ketorolac and nalbuphine infiltration compared with ropivacaine alone, the sample size was relatively small. Second, we did not encounter any potential 
LWI-related adverse events, due to a lack of enough power to detect differences in adverse events in our study. LWI, however, was not associated with any risk of wound infection. Third, our multimodal analgesic protocol consisted of sufentanil administration via PCIA. We recognize that sufentanil could enhance the analgesic effect of nalbuphine infiltration through synergy, thereby weakening the analgesic effect of ketorolac infiltration [28, 29]. This could have affected the comparison of outcomes between nalbuphine and ketorolac infiltration. Fourth, this study lacks the combination of two adjuvants used (produce precipitation) and intravenous control; therefore, we cannot verify the specific pathway (via systemic absorption or through perineural action) and demonstrate that opioids plus NSAIDs as a coadjuvant for LWI yield better analgesic effects. Fifth, the dose dependency and optimal dose were not determined in this study. Further research should investigate the optimal dose-effect relationship of adjuvant infiltration. Finally, the limited sample size from a single center and restrictive inclusion limit the generalization of the study. In addition, the findings may not be generalized to other institutions or other surgery types. The results should therefore be validated in a larger multicenter trial.

\section{CONCLUSIONS}

In conclusion, among patients undergoing open colorectal surgery, nalbuphine and ketorolac infiltration significantly prolonged analgesia duration and reduced morphine consumption compared with ropivacaine alone after surgery. Generally, the infiltration of these agents appears to be safe, but the results should be interpreted with caution as exploratory outcomes. However, ketorolac infiltration did not result in a clinically important improvement over nalbuphine infiltration, indicating that an equivalent analgesic dose of nalbuphine and ketorolac as local anesthetic adjuvants in LWI may have a similar analgesic effect.

\section{ACKNOWLEDGEMENTS}

We thank all patients who participated in the study and all the research staff.

Funding. This study was supported by the National Administration of Traditional Chinese Medicine: 2019 Project of building evidence based practice capacity for TCM [2019XZZXZL006] and Provincial Developmental Fund of Traditional Chinese Medicine-Key Discipline of TCM (Oncology of TCM) [2100601]. All funders had no role in study design, data collection, analysis, and interpretation, or preparation of the manuscript. The journal's Rapid Service Fee was funded by the authors.

Other Assistance. We would like to thank the China Academy of Chinese Medical Sciences, China Center for Evidence Based Traditional Chinese Medicine for financial support. We are especially grateful to Dr. Wei Shi (Department of Anesthesiology, West China Hospital, Sichuan University) for her statistical assistance and valuable advice during the preparation of the manuscript.

Authorship. All named authors meet the International Committee of Medical Journal Editors (ICMJE) criteria for authorship for this article, take responsibility for the integrity of the work as a whole, and have given their approval for this version to be published.

Authorship Contributions. Y-FR: conceptualization, methodology, writing-original draft. XF: methodology, writing-original draft. Y-TW: formal analysis, investigation, data curation. HL: visualization, formal analysis, software. $\mathrm{X}-\mathrm{ZZ}$ : formal analysis, software. JL: data curation, resources. L-JL: conceptualization, methodology, validation. F-MY: conceptualization, methodology, writing-review and editing.

Disclosures. Yi-Feng Ren, $\mathrm{Xi} \mathrm{Fu,} \mathrm{Yu-Ting}$ Wang, Hong Liu, Xiao-Zhen Zheng, Jing Liu, Lin-Jiong Li, and Feng-Ming You have nothing to disclose. 
Compliance with Ethics Guidelines. This LWINK study was approved by the ethics committee of Henan University, Jinming District, Kaifeng, China (reg. no. 2018LW012). The study was performed in accordance with the Helsinki Declaration of 1964 and its later amendments. The trial was registered at www. chictr.org.cn (registration number: ChiCTR1800019209). All participants consented to participate in this study and signed informed consent forms.

Data Availability. The data sets generated and/or analyzed during the current study are available from the corresponding author on reasonable request.

Open Access. This article is licensed under a Creative Commons Attribution-NonCommercial 4.0 International License, which permits any non-commercial use, sharing, adaptation, distribution and reproduction in any medium or format, as long as you give appropriate credit to the original author(s) and the source, provide a link to the Creative Commons licence, and indicate if changes were made. The images or other third party material in this article are included in the article's Creative Commons licence, unless indicated otherwise in a credit line to the material. If material is not included in the article's Creative Commons licence and your intended use is not permitted by statutory regulation or exceeds the permitted use, you will need to obtain permission directly from the copyright holder. To view a copy of this licence, visit http://creativecommons.org/licenses/by$\mathrm{nc} / 4.0 /$.

\section{REFERENCES}

1. Bamigboye AA, Hofmeyr GJ. Local anaesthetic wound infiltration and abdominal nerves block during caesarean section for postoperative pain relief. Cochrane Database Syst Rev. 2009. https:// doi.org/10.1002/14651858.CD006954.pub2: Cd006954.

2. Mohamed SA, Sayed DM, El Sherif FA, Abd El-Rahman AM. Effect of local wound infiltration with ketamine versus dexmedetomidine on postoperative pain and stress after abdominal hysterectomy, a randomized trial. Eur J Pain. 2018;22: 951-60.

3. Bai JW, An D, Perlas A, Chan V. Adjuncts to local anesthetic wound infiltration for postoperative analgesia: a systematic review. Reg Anesth Pain Med. 2020;45:645-55.

4. Ponce de León-Ballesteros G, Ramírez-Del Val A, Romero-Vélez G, et al. LAW Trial-the impact of local anesthetics infiltration in surgical wound for gastrointestinal procedures (LAW): a double-blind, randomized controlled trial. J Invest Surg. 2020;15: 14. https://doi.org/10.1080/08941939.2020. 1825885:1-6.

5. $\mathrm{Hu} \mathrm{QL}$, Dworsky JQ, Beck AC, et al. Perioperative pain management after ambulatory abdominal surgery: an American College of Surgeons Systematic Review. J Am Coll Surg. 2020. https://doi.org/ 10.1016/j.jamcollsurg.2020.07.755.

6. Englbrecht JS. Pogatzki-Zahn EM [Perioperative pain management for abdominal and thoracic surgery]. Schmerz. 2014;28:265-81.

7. Wiles MD, Nathanson MH. Local anaesthetics and adjuvants-future developments. Anaesthesia. 2010;65(Suppl 1):22-37.

8. Ren Y, Shi W, Chen C, et al. Efficacy of dexmedetomidine as an adjuvant to local wound infiltration anaesthesia in abdominal surgery: a meta-analysis of randomised controlled trials. Int Wound J. 2019;16:1206-13.

9. Amin OAI, Ibrahem MA, Salem DAE. Nalbuphine versus midazolam as an adjuvant to intrathecal bupivacaine for postoperative analgesia in patients undergoing cesarean section. J Pain Res. 2020;13: 1369-76.

10. Abdelhamid BM, Omar H. Nalbuphine as an adjuvant to $0.25 \%$ levobupivacaine in ultrasound-guided supraclavicular block provided prolonged sensory block and similar motor block durations (RCT). J Anesth. 2018;32:551-7.

11. Kalika P, Xue R, Zheng J, et al. Efficacy of nalbuphine as an adjuvant to ropivacaine in ultrasound-guided supraclavicular brachial block: a prospective randomized controlled study. Clin J Pain. 2020;36:267-72.

12. Akhlaghi N, Azarshab M, Akhoundi N, Meraji N. The effect of ketorolac buccal infiltration on postoperative endodontic pain: a prospective, doubleblind, randomized, controlled clinical trial. Quintessence Int. 2019;50:540-6. 
13. Aggarwal V, Singla M, Rizvi A, Miglani S. Comparative evaluation of local infiltration of articaine, articaine plus ketorolac, and dexamethasone on anesthetic efficacy of inferior alveolar nerve block with lidocaine in patients with irreversible pulpitis. J Endod. 2011;37:445-9.

14. Cormio L, Pagliarulo V, Lorusso F, et al. Combined perianal-intrarectal (PI) lidocaine-prilocaine (LP) cream and lidocaine-ketorolac gel provide better pain relief than combined PI LP cream and periprostatic nerve block during transrectal prostate biopsy. BJU Int. 2012;109:1776-80.

15. Connelly NR, Reuben SS, Albert M, Page D. Use of preincisional ketorolac in hernia patients: intravenous versus surgical site. Reg Anesth. 1997;22: 229-32.

16. Hayden JM, Oras J, Karlsson OI, et al. Post-operative pain relief using local infiltration analgesia during open abdominal hysterectomy: a randomized, double-blind study. Acta Anaesthesiol Scand. 2017;61:539-48.

17. Zhang P, Liu S, Zhu J, Rao Z, Liu C. Dexamethasone and dexmedetomidine as adjuvants to local anesthetic mixture in intercostal nerve block for thoracoscopic pneumonectomy: a prospective randomized study. Reg Anesth Pain Med. 2019. https://doi.org/10.1136/rapm-2018-100221.

18. Thybo KH, Hägi-Pedersen D, Dahl JB, et al. Effect of combination of paracetamol (Acetaminophen) and ibuprofen vs either alone on patient-controlled morphine consumption in the first 24 hours after total hip arthroplasty: the PANSAID Randomized Clinical Trial. JAMA. 2019;321:562-71.

19. Subramaniam B, Shankar P, Shaefi S, et al. Effect of intravenous acetaminophen vs placebo combined with propofol or dexmedetomidine on postoperative delirium among older patients following cardiac surgery: the DEXACET Randomized Clinical Trial. JAMA. 2019;321:686-96.

20. Jakobsen JC, Gluud C, Wetterslev J, Winkel P. When and how should multiple imputation be used for handling missing data in randomised clinical trials-a practical guide with flowcharts. BMC Med Res Methodol. 2017;17:162.

21. Hirota K, Okawa H, Appadu BL, Grandy DK, Lambert DG. Interaction of local anaesthetics with recombinant mu, kappa, and delta-opioid receptors expressed in Chinese hamster ovary cells. $\mathrm{Br} \mathrm{J}$ Anaesth. 2000;85:740-6.

22. Ko MC, Naughton NN, Traynor JR, et al. Orphanin FQ inhibits capsaicin-induced thermal nociception in monkeys by activation of peripheral ORL1 receptors. Br J Pharmacol. 2002;135:943-50.

23. Iwaszkiewicz KS, Schneider JJ, Hua S. Targeting peripheral opioid receptors to promote analgesic and anti-inflammatory actions. Front Pharmacol. 2013;4:132.

24. Brummett CM, Williams BA. Additives to local anesthetics for peripheral nerve blockade. Int Anesthesiol Clin. 2011;49:104-16.

25. Bailard NS, Ortiz J, Flores RA. Additives to local anesthetics for peripheral nerve blocks: evidence, limitations, and recommendations. Am J Health Syst Pharm. 2014;71:373-85.

26. Vuilleumier PH, Schliessbach J, Curatolo M. Current evidence for central analgesic effects of NSAIDs: an overview of the literature. Minerva Anestesiol. 2018;84:865-70.

27. Chiruvella S, Konkyana SK, Nallam SR, Sateesh G. Supraclavicular brachial plexus block: comparison of varying doses of nalbuphine combined with levobupivacaine: a prospective, double-blind, randomized trial. Anesth Essays Res. 2018;12:135-9.

28. Pasternak GW. Preclinical pharmacology and opioid combinations. Pain Med. 2012;13(Suppl 1):S411.

29. Miranda HF, Silva E, Pinardi G. Synergy between the antinociceptive effects of morphine and NSAIDs. Can J Physiol Pharmacol. 2004;82:331-8. 